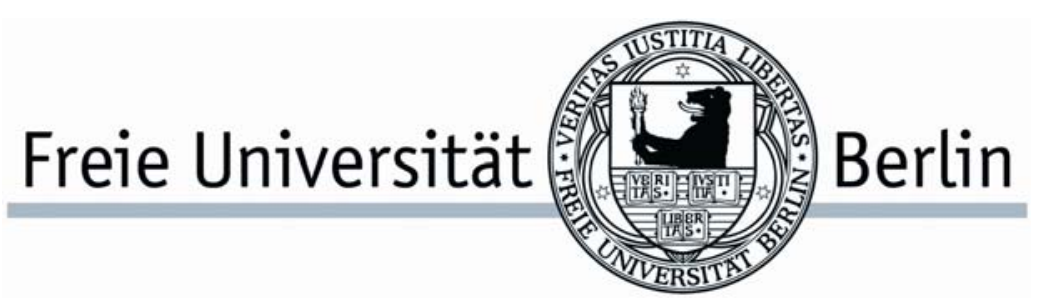

Diskussionsbeiträge des Fachbereichs Wirtschaftswissenschaft der Freien Universität Berlin

Volkswirtschaftliche Reihe

2009/1

\title{
Global Rebalancing in a Three-Country Model
}

\author{
Philipp Engler
}

ISBN 3-938369-95-7 


\title{
Global Rebalancing in a Three-Country Model
}

\author{
Philipp Engler ${ }^{1}$
}

March 7, 2009

\begin{abstract}
This paper extends the model of Engler et al. (2007) on the adjustment of the US current account to a three-country world economy. This allows an analysis of the differential impact of a reversal of the US current account on Europe and Asia. In particular, the outcomes under different exchange rate policies are analysed. The main finding is that large factor re-allocations from non-tradables to tradables will be necessary in the US. The direction of factor re-allocation in Asia depends on whether the "Bretton-Woods-II" regime of unilaterally fixed or manipulated exchange rates in Asia is continued. If this is the case, the tradables sector and the current account surplus will continue to grow even when the US deficit closes. The flip side of this result is that Europe will face a huge real appreciation and an enormous current account deficit. With floating exchange rates worldwide, the impact on Europe will be limited while Asia's tradables sector will shrink.
\end{abstract}

JEL: E2, F32, F41.

Keywords: Global imbalances, US current account deficit, dollar adjustment, sectoral adjustment

\footnotetext{
Contact details: Freie Universität Berlin, School of Business and Economics, Boltzmannstr. 20, Room 232, 14195 Berlin, Germany, philipp.engler@fu-berlin.de. I thank Helge Berger for many helpful suggestions. Any remaining errors are the responsibility of the author.
} 


\section{Introduction}

Global current account positions have become remarkable in their size and configuration in recent years. Looking at the size, the sum of deficits has grown to almost $2 \%$ of world GDP in 2006 (Figure 1) ${ }^{1}$, a figure unmatched in the history of international economic integration. Hence, globalization is clearly at work. The deficits have started to decline since 2006, but aggregate surpluses have not. The question that ultimately comes to commentators' minds is whether, and under which conditions, this development will last or reverse and what the consequences of the possible scenarios might be. These topics have been hotly debated in recent years.

Looking at the configuration, the single country contributing most (and almost entirely from a global perspective when the euro-area is taken as an entity) to the "global deficit" is the United States while the creditor side is taken mainly by the oil exporters and Asian economies. The US deficit reached a peak of 1.6\% of world GDP in both 2005 and 2006 but is expected to have shrunk by around one third to $1.1 \%$ in 2008 . This points to the critical dependence of the world economy on developments in a single country. Not surprisingly, in recent analyses of current imbalances and its unwinding that has now begun, the US economy and its role in the world economy took center stage.

Figure 1: Global Current Account configuration (\% of world GDP; Source: ECB)

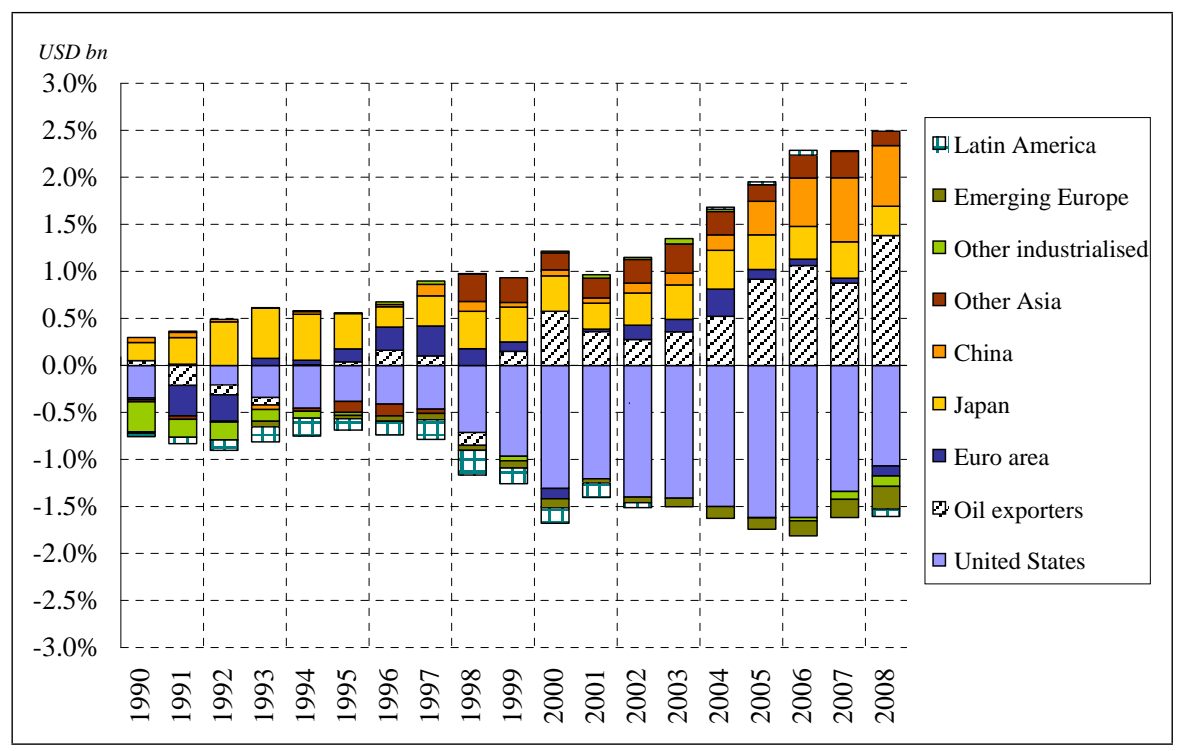

This paper takes a three-country view of imbalances in which the United States,

\footnotetext{
1 Actual numbers would be even higher if individual countries were displayed rather than groups of countries, as in Figure 1. However, this categorization helps to focus on broader patterns of the current configuration.
} 
Asia and Europe add up to a hypothetical world economy. Therein, different rebalancing scenarios are analyzed. In a related paper, Engler et al. (2007) extended the analysis by Obstfeld and Rogoff (2006) taking account of supply side changes, rather than purely demand-switching in an endowment economy, through which the exchange rate implications of a closing of the US current account are moderated. In particular, a re-allocation of factors from non-tradable towards tradable goods sectors in the United States and vice versa in the rest of the world is induced by the adjustment. With regard to the United States, this would stop the last decade's trend towards an ever increasing share of non-tradables in total output. This quantity adjustment severely reduced the implied adjustment of real exchange rates in a two-country framework (the United States and the rest of the world).

What this two-country-approach cannot capture is the differential impact on different regions in the hypothetical rest of the world, in particular under differential exchange rate policies in a rebalancing scenario. Many Asian central banks intervene heavily in foreign exchange markets or fix their currencies in order to keep their currencies undervalued relative to the US dollar, while the US dollar floats vis-à-vis other industrialized countries' currencies. Hence, the relative exchange rate and quantity adjustments in different parts of the world are likely to be affected by such differential policies.

The core result of this paper is that the effect of continuing interventions on the side of Asian central banks severely shifts the burden of adjustment of a closing of the US current account deficit to Europe. In particular, the fixed exchange rates, or in other words, the joint depreciation of Asian currencies with the dollar vis-à-vis the euro, result in a complete reversal of the sectoral adjustment in Asia in a rebalancing scenario compared to a flexible exchange rate scenario. Rather than reducing the relative size of the tradables sector as in the case of flexible exchange rates, it further increases it, even more than in the case of an endowment economy. The flip side of this result is that the European non-tradables sector needs to increase much more relative to the tradables sector implying a large factor reallocation. This change in relative size of sectors is much larger than in the case of fixed supplies. Hence, European economies will be tested severely in a rebalancing in which Asia keeps its peg vis-à-vis the US dollar. For instance, countries with inflexible labor markets might see an increase in unemployment. And, both by implication and by assumption, Asia will build up a massive current account surplus vis-à-vis Europe of up to $11 \%$ of US GDP.

The most recent developments in the world financial system point to an unwinding solution that is somewhere between the pure Bretton-Woods scenario and a scenario under flexible exchange rates. China has not abandoned its peg, while the Japanese yen has appreciated significantly. Although it is too early for an overall assessment, a severe risk to the world economy consists in insufficient flexibility in goods and factor markets, in particular in many European countries. This might potentially lead to large increases in unemployment and exert, in addition to the purely economic stress, increased political pressure on the current world trade and financial system.

The paper is structured as follows: Section 2 lays out the theoretical framework used for the analysis. Section 3 presents and discusses the results for different adjustment scenarios, and Section 4 concludes. 


\section{The Model}

This paper extends the model in Engler et al. (2007) in a crucial dimension. Not only does it introduce a supply side channel mitigating the exchange rate implications of an unwinding of global imbalances, which is an extension to the Obstfeld and Rogoff (2006) model. It also differentiates between regions in the "rest of the world". The heterogeneity of the rest of the world is made explicit in a three-country setting as in Obstfeld and Rogoff (2005), incorporating a "European" and an "Asian" economy as well as the United States (denoted by E, A and U respectively). Thus, the effects of a rebalancing on goods and factor markets can be assessed from the perspective of countries/regions and which may follow different exchange rate policies. ${ }^{2}$

The experiment is to analyze the effects of a closing of the US current account deficit. What is implicitly assumed is that there are either policy-induced or financial market-induced changes relative to the current situation. It could be that Asian central banks or financial markets are no longer willing to finance the US deficit. Hence, this analysis does not rest on any particular explanation for the current situation, it rather assumes that the stabilizing forces for the US deficit no longer prevail.

The main contribution from this approach is that European goods and factor markets will be severely tested if Asian central banks continue to fix their US dollar exchange rates under a rebalancing scenario, while European currencies continue to float vis-àvis the US dollar. Real effective exchange rates continue to be less affected because of the supply response, but the terms of trade change a lot more. The direction and extent of the implied change in trade flows crucially depends on exchange rate regimes. A lack of willingness in Asia to share the burden of the necessary trade adjustment shifts this burden entirely to the European economies, thereby shrinking the European tradables sector remarkably.

The model is built around standard supply and demand sides. Each region produces a non-tradable and a tradable good with Cobb-Douglas production functions with labor as the only input. Labor markets are assumed to be perfectly integrated within countries (but not between countries), hence labor flows freely between the tradables and the non-tradables sectors and a single wage rate prevails within each country. Demand functions are derived from CES consumption indexes and depend on the current account balances of the respective country. Hence the current accounts, defined as the difference between tradables production and tradables consumption plus the income balance, can be interpreted as budget constraints.

Equilibrium prices and quantities for given current account balances are computed by equating supply and demand of each good. When two sets of equilibrium prices and quantities are determined, each for a certain configuration of current accounts, these sets of equilibrium prices and quantities can be compared and price and quantity changes be calculated for the assumed change of current accounts. In particular, I determine the changes of real exchange rates, the terms of trade, the relative price

2 These terms should not be taken too literally since in the calibration "Europe" is rather a group of countries with flexible exchange rates, which also contains a few non-European countries (Canada, Australia and New Zealand). But since the European Union plus other European non-EU countries form by far the most important block, the term "Europe" serves as a good proxy for the countries in this group. 
of non-tradables, relative non-tradables quantities and the relative tradables quantities across countries.

Regarding relative supplies, I assume the same relative quantities as Obstfeld and Rogoff (2005) in the original allocation (i.e., with the US current account deficit), but let them adjust together with relative prices in the simulations of changes in current accounts. Using the same original allocation allows a direct comparison of results and the impact of supply responses in a rebalancing scenario.

Because I assume a frictionless factor re-allocation between sectors, my results can be regarded as a limiting case, just as the endowment economy assumed by Obstfeld and Rogoff (2005) is a limiting case for complete inflexibility on the supply side. Any real world adjustment is likely to be somewhere between these two extremes, and the closeness of actual results to the two extremes will be determined by a number of factors that cannot be made explicit in the present framework. One important factor will be time, that is, whether a financial market crash makes a quick closing of the US current account necessary leaving little time for factor and goods markets to adjust or whether the adjustment occurs over a longer time span. Closely related is the degree of factor market rigidities that will determine to what extent the re-allocation is possible in a given time.

The demand side and the supply side are introduced below, then a general equilibrium is defined and determined.

\subsection{The Demand Side}

Each country's preferences for tradable and non-tradable goods are described by constant elasticity of substitution (CES) consumption indexes,

$$
C^{i}=\left[\gamma^{\frac{1}{\theta}}\left(C_{T}^{i}\right)^{\frac{\theta-1}{\theta}}+(1-\gamma)^{\frac{1}{\theta}}\left(C_{N}^{i}\right)^{\frac{\theta-1}{\theta}}\right]^{\frac{\theta}{\theta-1}}, \quad i=U, E, A
$$

where $C_{T}^{i}$ and $C_{N}^{i}$ are consumption of tradables and non-tradables in region $i$ respectively, $\gamma$ is a weighting factor and $\theta$ the elasticity of substitution between tradables and non-tradables. Below, the focus will be on the special case of $\theta=1$, for which this index simplifies to

$$
C^{i}=\frac{\left(C_{T}^{i}\right)^{\gamma}\left(C_{N}^{i}\right)^{1-\gamma}}{\gamma^{\gamma}(1-\gamma)^{1-\gamma}}, \quad i=U, E, A
$$

The $C_{T}^{i}$ in turn are indexes of the three tradable goods produced in the three regions,

$$
\begin{aligned}
C_{T}^{U} & =\left[\alpha^{\frac{1}{\eta}}\left(C_{U}^{U}\right)^{\frac{\eta-1}{\eta}}+(\beta-\alpha)^{\frac{1}{\eta}}\left(C_{E}^{U}\right)^{\frac{\eta-1}{\eta}}+(1-\beta)^{\frac{1}{\eta}}\left(C_{A}^{U}\right)^{\frac{\eta-1}{\eta}}\right]^{\frac{\eta}{\eta-1}}, \\
C_{T}^{E} & =\left[\alpha^{\frac{1}{\eta}}\left(C_{E}^{E}\right)^{\frac{\eta-1}{\eta}}+(\beta-\alpha)^{\frac{1}{\eta}}\left(C_{U}^{E}\right)^{\frac{\eta-1}{\eta}}+(1-\beta)^{\frac{1}{\eta}}\left(C_{A}^{E}\right)^{\frac{\eta-1}{\eta}}\right]^{\frac{\eta}{\eta-1}}
\end{aligned}
$$


and

$$
C_{T}^{A}=\left[\delta^{\frac{1}{\eta}}\left(C_{A}^{A}\right)^{\frac{\eta-1}{\eta}}+\left(\frac{1-\delta}{2}\right)^{\frac{1}{\eta}}\left(C_{E}^{A}\right)^{\frac{\eta-1}{\eta}}+\left(\frac{1-\delta}{2}\right)^{\frac{1}{\eta}}\left(C_{U}^{A}\right)^{\frac{\eta-1}{\eta}}\right]^{\frac{\eta}{\eta-1}}
$$

with $\alpha$ determining the degree of home-bias in tradables consumption in the United States and Europe and $\delta$ in Asia. The term $1-\beta$ is a preference parameter for consumption of Asia's tradable good in the United States and Europe and $\eta$ is the elasticity of substitution between the different goods in the indexes. This parameterization indicates that the United States and Europe have identical preferences for Asia's tradable good, while Asia gives equal weight to both the United States' and Europe's goods.

From these consumption indexes, standard price indexes can be derived. For overall consumption in the three regions, these are the broad consumer price indexes (CPIs)

$$
P_{C}^{i}=\left[\gamma\left(P_{T}^{i}\right)^{1-\theta}+(1-\gamma)\left(P_{N}^{i}\right)^{1-\theta}\right]^{\frac{1}{1-\theta}}, \quad i=U, E, A
$$

which for $\theta=1$ simplify to

$$
P_{C}^{i}=\left(P_{T}^{i}\right)^{\gamma}\left(P_{N}^{i}\right)^{1-\gamma}, \quad i=U, E, A
$$

and where

and

$$
\begin{aligned}
& P_{T}^{U}=\left[\alpha P_{U}^{1-\eta}+(\beta-\alpha) P_{E}^{1-\eta}+(1-\beta) P_{A}^{1-\eta}\right]^{\frac{1}{1-\eta}}, \\
& P_{T}^{E}=\left[\alpha P_{E}^{1-\eta}+(\beta-\alpha) P_{U}^{1-\eta}+(1-\beta) P_{A}^{1-\eta}\right]^{\frac{1}{1-\eta}},
\end{aligned}
$$

$$
P_{T}^{A}=\left[\delta P_{A}^{1-\eta}+\left(\frac{1-\delta}{2}\right) P_{U}^{1-\eta}+\left(\frac{1-\delta}{2}\right) P_{E}^{1-\eta}\right]^{\frac{1}{1-\eta}}
$$

with $P_{T}^{i}$ and $P_{N}^{i}$ denoting the price indexes of tradable goods and the price of the nontradable good in country $i$ while the $P_{i}$ 's are the prices of the tradable goods produced in region $i$. All prices are in terms of US dollars and the law of one price holds, that is, each tradable good has the same price in all regions when expressed in the same currency. However, purchasing power parity in terms of aggregate prices does not hold because CPIs differ across regions.

Relative Prices Below, we need the terms of trade, the relative prices of nontradables and the real exchange rates. The bilateral terms of trade are defined as the relative price of the respective tradable goods,

$$
\tau_{U, E}=\frac{P_{E}}{P_{U}}, \quad \tau_{U, A}=\frac{P_{A}}{P_{U}} \text { and } \tau_{E, A}=\frac{P_{A}}{P_{E}}=\frac{\tau_{U, A}}{\tau_{U, E}}
$$


while the relative prices of non-tradables ("internal terms of trade") are

$$
\iota_{U}=\frac{P_{N}^{U}}{P_{U}}, \quad \iota_{E}=\frac{P_{N}^{E}}{P_{E}} \text { and } \iota_{A}=\frac{P_{N}^{A}}{P_{A}} .
$$

Bilateral real exchange rates are defined as the ratios of respective CPIs,

$$
q_{U, E}=\frac{P_{C}^{E}}{P_{C}^{U}}, q_{U, A}=\frac{P_{C}^{A}}{P_{C}^{U}} \text { and } q_{E, A}=\frac{P_{C}^{A}}{P_{C}^{E}}=\frac{q_{U, A}}{q_{U, E}}
$$

where $q_{i, j}$ is the relative price of region $j$ 's consumption in terms of region $i$ 's consumption.

Bilateral real exchange rates can be shown to be functions of the terms of trade and the relative prices of non-tradables. For the special case of $\theta=1^{3}$, these simplify to

$$
q_{U, E}=\left[\frac{\alpha \tau_{U, E}^{1-\eta}+(\beta-\alpha)+(1-\beta) \tau_{U, A}^{1-\eta}}{\alpha+(\beta-\alpha) \tau_{U, E}^{1-\eta}+(1-\beta) \tau_{U, A}^{1-\eta}}\right]^{\frac{\gamma}{1-\eta}}\left(\frac{\iota_{E}}{\iota_{U}} \tau_{U, E}\right)^{1-\gamma}
$$

and

$$
q_{U, A}=\left[\frac{\delta \tau_{U, A}^{1-\eta}+\left(\frac{1-\delta}{2}\right)+\left(\frac{1-\delta}{2}\right) \tau_{U, E}^{1-\eta}}{\alpha+(\beta-\alpha) \tau_{U, E}^{1-\eta}+(1-\beta) \tau_{U, A}^{1-\eta}}\right]^{\frac{\gamma}{1-\eta}}\left(\frac{\iota_{A}}{\iota_{U}} \tau_{U, A}\right)^{1-\gamma}
$$

Noticing that $\frac{\iota_{E}}{\iota_{U}} \tau_{U, E}=\frac{P_{N}^{E}}{P_{N}^{U}}$, it is obvious that the relative influence of the terms of trade and the relative prices of non-tradables across countries is determined by the weight of tradables and non-tradables consumption in the consumption index $\gamma$ and $1-\gamma$. With a much greater weight for the latter as observed in most countries, changes in bilateral real exchange rates are mainly driven by changes in relative prices of nontradables and to a lesser extent by changes in the terms of trade. Hence, a neglect of non-tradables would be a severe drawback in an analysis of current account rebalancing.

Real effective exchange rates are weighted relative CPIs and can be expressed as weighted bilateral real exchange rates:

$$
\begin{aligned}
q^{U} & =\left(q_{U, E}^{\beta-\alpha}\right)\left(q_{U, A}^{1-\beta}\right), \\
q^{E} & =\left(\begin{array}{c}
\alpha-\beta \\
q_{U, E}
\end{array}\right)\left(\begin{array}{c}
1-\beta \\
q_{E, A}
\end{array}\right)
\end{aligned}
$$

3 For the general case of $\theta \neq 1$ the reader is referred to Appendix A. 
and

$$
q^{A}=\left(q_{U, A}^{-\frac{1}{2}}\right)\left(q_{E, A}^{-\frac{1}{2}}\right)
$$

In order to derive nominal exchange rates from the above exercise, further assumptions need to be made. Central banks can follow one of two possible strategies in this framework, CPI-targeting (i.e., keeping the overall CPI-index constant over time), or GDP-deflator-targeting (i.e., keeping a weighted average of domestically produced goods prices constant over time). In the first case, nominal exchange rates move one for one with real exchange rates. In the second case, one could specify monetary policy by assuming that central banks fix a geometric average of domestically produced tradables and non-tradables. However, results are quantitatively not very different between the two monetary policy regimes (CPI- and GDP-deflator-targeting), thus there is also no big difference between nominal and real exchange rates, no matter what policy I assume. In the analysis below, I therefore only report results for real exchange rates under the assumption of CPI-targeting.

Demand Functions Nominal demands for non-tradable goods, expressed as functions of tradable goods consumption, are

and

$$
\begin{aligned}
& P_{N}^{U} Y_{N}^{U}=\frac{1-\gamma}{\gamma}\left(\frac{P_{N}^{U}}{P_{T}^{U}}\right)^{1-\theta} P_{T}^{U} C_{T}^{U}, \\
& P_{N}^{E} Y_{N}^{E}=\frac{1-\gamma}{\gamma}\left(\frac{P_{N}^{E}}{P_{T}^{E}}\right)^{1-\theta} P_{T}^{E} C_{T}^{E}
\end{aligned}
$$

$$
P_{N}^{A} Y_{N}^{A}=\frac{1-\gamma}{\gamma}\left(\frac{P_{N}^{A}}{P_{T}^{A}}\right)^{1-\theta} P_{T}^{A} C_{T}^{A}
$$

For tradables, in turn, these are

$$
\begin{aligned}
P_{U} Y_{T}^{U}= & \alpha\left(\frac{P_{U}}{P_{T}^{U}}\right)^{1-\eta} P_{T}^{U} C_{T}^{U}+(\beta-\alpha)\left(\frac{P_{U}}{P_{T}^{E}}\right)^{1-\eta} P_{T}^{E} C_{T}^{E} \\
& +\frac{1-\delta}{2}\left(\frac{P_{U}}{P_{T}^{A}}\right)^{1-\eta} P_{T}^{A} C_{T}^{A} \\
P_{E} Y_{T}^{E}= & \alpha\left(\frac{P_{E}}{P_{T}^{E}}\right)^{1-\eta} P_{T}^{E} C_{T}^{E}+(\beta-\alpha)\left(\frac{P_{E}}{P_{T}^{U}}\right)^{1-\eta} P_{T}^{U} C_{T}^{U} \\
& +\frac{1-\delta}{2}\left(\frac{P_{E}}{P_{T}^{A}}\right)^{1-\eta} P_{T}^{A} C_{T}^{A}
\end{aligned}
$$


Walras' law determines the demand function for Asia's tradables.

Because these demand functions are expressed in terms of tradables consumption, they can be related to the regions' current accounts. The current account of region $i, C U^{i}$, is defined as tradables output minus tradables consumption plus the income balance, defined as the return $r$ received on the region's net foreign assets $F^{i}$. Hence, for the United States and Europe we have

$$
C A^{U}=P_{U} Y_{T}^{U}-P_{T}^{U} C_{T}^{U}+r F^{U}
$$

and

$$
C A^{E}=P_{E} Y_{T}^{E}-P_{T}^{E} C_{T}^{E}+r F^{E}
$$

From an accounting perspective, current accounts and stocks of net foreign assets need to add up to zero globally, therefore

$$
C A^{U}+C A^{E}+C A^{A}=0
$$

and

$$
F^{U}+F^{E}+F^{A}=0
$$

Consequently, for Asia's current account we have

$$
C A^{A}=-\left(C A^{U}+C A^{E}\right)=P_{A} Y_{T}^{A}-P_{T}^{A} C_{T}^{A}-r\left(F^{U}+F^{E}\right) .
$$

Using these definitions and normalizing all demand functions by the US tradable output $P_{U} Y_{T}^{U}$ we get the five equations shown in Appendix A. They fully describe the demand side of the model. Next, I determine the supply side.

\subsection{The Supply Side}

The supply side is introduced by simple Cobb-Douglas production functions for the six goods with labor as the only input,

$$
Y_{i}^{j}=A_{i}^{j}\left(L_{i}^{j}\right)^{\nu} \quad \text { for } i=T, N \text { and for } j=U, E, A
$$

with $A_{i}^{j}$ and $L_{i}^{j}$ denoting total factor productivity and labor input in region $j$ 's sector $i$ while $\nu$ is labor's marginal productivity. The nested case of a fixed supply is $\nu=0$ while $\nu=1$ denotes the constant returns case. Labor is assumed to be mobile across 
sectors within regions but immobile across regions. Hence, a single nominal wage rate $\omega^{j}$, expressed in terms of US dollars, exists for each region $j$. For simplicity, total labor input in region $j, L^{j}=L_{T}^{j}+L_{N}^{j}$, is assumed to be constant over time.

The following relative domestic supply relations are derived from firms' profit maximization:

$$
\frac{P_{N}^{U} Y_{N}^{U}}{P_{U} Y_{T}^{U}}=\left(\frac{A_{N}^{U}}{A_{T}^{U}} \iota_{U}\right)^{\frac{1}{1-\nu}}
$$

for the United States and for Europe and Asia accordingly

$$
\frac{P_{N}^{E} Y_{N}^{E}}{P_{E} Y_{T}^{E}}=\left(\frac{A_{N}^{E}}{A_{T}^{E}} \iota_{E}\right)^{\frac{1}{1-\nu}}
$$

and

$$
\frac{P_{N}^{A} Y_{N}^{A}}{P_{A} Y_{T}^{A}}=\left(\frac{A_{N}^{A}}{A_{T}^{A}} \iota_{A}\right)^{\frac{1}{1-\nu}} .
$$

Hence, the relative supply of non-tradables is a positive function of its relative price and relative total factor productivities.

Tradable output in Europe and Asia relative to US tradable output can be shown to be

$$
\frac{P_{E} Y_{T}^{E}}{P_{U} Y_{T}^{U}}=\left[\left(\frac{w^{E}}{w^{U}}\right)^{-\nu} \tau_{U, E} \frac{A_{T}^{E}}{A_{T}^{U}}\right]^{\frac{1}{1-\nu}}
$$

and

$$
\frac{P_{A} Y_{T}^{A}}{P_{U} Y_{T}^{U}}=\left[\left(\frac{w^{A}}{w^{U}}\right)^{-\nu} \tau_{U, A} \frac{A_{T}^{A}}{A_{T}^{U}}\right]^{\frac{1}{1-\nu}}
$$

Because of differing wages across countries, bilateral relative tradables supply is, in addition to the terms of trade and relative total factor productivities, also a function of relative wages. These in turn are

$$
\frac{\omega^{E}}{\omega^{U}}=\left(\frac{L^{U}}{L^{E}}\right)^{1-\nu}\left[\frac{1+\left(\iota_{E} \frac{A_{N}^{E}}{A_{T}^{E}}\right)^{\frac{1}{1-\nu}}}{1+\left(\iota_{U} \frac{A_{N}^{U}}{A_{T}^{U}}\right)^{\frac{1}{1-\nu}}}\right]^{1-\nu} \tau_{U, E} \frac{A_{T}^{E}}{A_{T}^{U}}
$$


and

$$
\frac{\omega^{A}}{\omega^{U}}=\left(\frac{L^{U}}{L^{A}}\right)^{1-\nu}\left[\frac{1+\left(\iota_{A} \frac{A_{N}^{A}}{A_{T}^{A}}\right)^{\frac{1}{1-\nu}}}{1+\left(\iota_{U} \frac{A_{N}^{U}}{A_{T}^{U}}\right)^{\frac{1}{1-\nu}}}\right]^{1-\nu} \tau_{U, A} \frac{A_{T}^{A}}{A_{T}^{U}}
$$

The supply side is fully described by the relative supply functions (1) through (5) and the relative wage equations (6) and (7).

\subsection{General Equilibrium}

In a general equilibrium, goods markets clear in the six markets. For deriving equilibrium conditions, we only need to equate relative demand and supply relations. By doing so, we derive solutions for all relative prices and relative quantities, which are calculated for given current account positions. The resulting equations (shown in Appendix B) and the relative wage equations (6) and (7) describe the general equilibrium.

\section{Rebalancing of the US Current Account}

Having set up the model, it can now be used for simulations of different scenarios in which the US current account deficit is closed. The modelling strategy is to compute two equilibria for every scenario, one with the original global imbalances in which the United States have a current account deficit, and one for which these imbalances are reduced. In most cases, all current accounts are set to zero. Then, the percent changes of relative prices and quantities are computed.

After explaining the calibration of the model in Section 3.1, results are summarized along two dimensions. The first dimension, discussed in Section 3.2, relates to the comparison with the results presented in Obstfeld and Rogoff, the benchmark with no supply adjustment ${ }^{4}$. The second dimension, presented in Section 3.3, relates to the comparison between the two possible exchange rate regimes: the "Global Rebalancing" regime where all exchange rates are freely floating and the "Bretton-Woods-II" regime in which Asia pegs its exchange rate to the US dollar. ${ }^{5}$ In a snapshot, results for these two dimensions are summarized in Figures 2-5, while detailed results are presented in Tables 1 and 2 in Appendix C.

The two main results from this analysis are (1) that the supply adjustment reduces the exchange rate implications of the re-balancing, thereby shifting the burden of adjustment towards the real economy, while (2) the choice of the exchange rate regime

\footnotetext{
4 Note that most of Obstfeld and Rogoff's results include valuation effects, that is, the effects of exchange rate changes on the stocks and flows of gross assets and liabilities. These valuation effects, in turn, influence the amount of required trade and price adjustment. It turns out, however, that assuming quite plausible interest rate changes, in particular a reduction in the "exorbitant privilege" (the lower interest rate paid on US liabilities relative to the interest rate received from foreign asset holdings), has the opposite effect of the valuation changes. Hence, these two extensions may well offset each other completely. Therefore, I do not analyse these additional effects and concentrate on the supply side effects.

5 See Dooley et al. (2003, 2004a-c, 2005a-b) and Caballero et al. (2006, 2007) for discussions about an exchange rate peg or the stable exchange rates between the United States and Asian economies.
} 
has important implications for the burden sharing between different regions. In particular, Europe is likely to bear the brunt of this burden if Asia keeps its peg with the dollar.

Alongside the main specifications, a number of extensions are discussed. First, the sensitivity of the adjustment to the size of the required change of the current account positions is analyzed (Table 1). This is done by showing results for the case of a reduction to one half of the original current account positions (rather than setting them to zero as in the benchmark scenario). Second, the sensitivity of the adjustment to the time over which this adjustment needs to occur is highlighted (Table 2). This is done by increasing the elasticities of substitution between different goods. This modelling approach can be justified by assuming that with more time to adjust, more substitutions in response to relative price changes are possible, which can be captured by a larger elasticity of substitution. And finally, the role of a growing Asian labor force is discussed.

\subsection{Calibration}

In order to make results comparable with the benchmark model in Obstfeld and Rogoff (2005), parameters are chosen as in their framework. However, since the time frame involved in a supply adjustment is likely to be larger and hence elasticities larger than in an abrupt rebalancing, bigger elasticities are discussed as well.

The most important parameters are the elasticities of substitution between tradable goods and non-tradable goods, $\theta$, and between tradable goods from different countries, $\eta$. Most studies find relatively low values for $\theta$, usually between 0.5 and 1 (see Mendoza, 1991 and Stockman and Tesar, 1995). I follow Obstfeld and Rogoff (2005) who chose $\theta=1$ at the upper end of this range to capture the short term adjustment scenario, but I also report results for $\theta=2$ in order to capture longer periods in which adjustment might take place. In the benchmark specification, I choose $\eta=2$ which is in the middle range of values usually employed and $\eta=4$ for the slow adjustment scenario.

The share of tradables consumption in total consumption, $\gamma$, is set to 0.25 , a value that corresponds roughly with the OECD average of tradable output share (Engler et al., 2006). Therefore, the relative quantities of non-tradables and tradables are set to 3 in all regions in the initial allocation. The relative tradables quantities across regions are set to 1 , and $\alpha, \beta$ and $\delta$ are set to $0.7,0.8$ and 0.7 respectively. Hence, all regions have an equal home-bias in tradables consumption of $0.7^{6}$ while the United States and Europe weigh Asia's tradables somewhat more than Asia weighs their exports. This implies that Asia is assumed to play an important role in world trade.

The elasticity of output with respect to the factor input, $\nu$, is the critical parameter that distinguishes this framework from Obstfeld and Rogoff's benchmark. In that benchmark, this parameter takes on the value of 0 , which does not allow any supply adjustment. The results of this benchmark are compared with results when supply is allowed to adjust. As a standard value I choose $\nu=0.7$, which roughly corresponds to

\footnotetext{
6 This value is slightly smaller than the one discussed for OECD countries in Obstfeld and Rogoff (2000).
} However, I follow Obstfeld and Rogoff (2005) with their choice in order to guarantee comparabilita of results. 
the US labor share. As a robustness check, I present the constant returns to scale case where $\nu=1$ for some specifications.

The US current account relative to its own tradable output, $c a^{U}$, is assumed to be -0.2 in the original allocation from which the adjustment begins. Assuming a tradables share of about $25 \%$ in total GDP, this implies a current account to GDP ratio of -0.05 . This corresponds to a little less than the actual figure in 2007.

An important element of this model are the relative total labor inputs $\frac{L^{i}}{L^{j}}$. Note that although initially one may view this term as endogenous because changes in hours are likely to occur in an adjustment process, consistency requires treating it as constant in the framework I apply. As I abstract from consumers' and workers' intertemporal optimization decisions, I hold total real consumption and total real output constant, and adjust only relative quantities. Hence, total labor supply needs to be constant, too. This allows analyzing sectoral adjustment without modeling total demand and supply.

Two aspects matter for my choice of population figures. First, data on hours worked is available for OECD countries, but not for most developing countries. Hence, relative hours can only be proxied, at least for the US-Asia relationship. Therefore, I use World Development Indicators data of the World Bank on relative populations for all three regions in order to guarantee consistency. In the "European" labor force, I include the European Union, Turkey, Switzerland, Canada, Australia and New Zealand. The rationale for this choice is that Obstfeld and Rogoff (2005) include the later four countries for their determination of portfolio shares and because Turkey can well be regarded as part of the wider European economy with its decades old currency union with the European Union. Having flexible exchange rates, this group of countries is likely to be affected similarly in a rebalancing scenario and differentially vis-à-vis the Asian economies, many of which stabilize nominal exchange rates and thereby add to the burden of adjustment on the "European" side.

Second, major Asian countries have a huge share of rural populations which may not be considered as a part of the population relevant for the modern economy and in which substitution between tradable and non-tradable sectors occurs. In the case of China and Thailand, the shares of the urban populations are as low as $44 \%$ and $24 \%$ respectively in 2007. Hence, I adjust the developing Asian economies' population figures by considering only urban populations. The countries included are China, India, Indonesia, Japan, the Philippines, Vietnam, Thailand, Korea, Malaysia and Singapore, furthermore Taiwan and Hongkong. In order to guarantee consistency, I use urban populations for Europe and the United States as well. It turns out, however, that results are not very sensitive to the exact figure.

In a robustness check, I want to grasp the current population dynamics in Asian societies with a rapid growth of urban populations of up to $4.4 \%$ in case of Indonesia and 3.6\% in China. This changes the relative population figures over time and therefore the results of the supply adjustment simulations. I provide simulation results only for the longer adjustment scenarios where I computed the changing urban populations over a five-year horizon beginning in 2005 , assuming the average annual growth rates of the time between 1990 and 2004. The resulting figures can thus be regarded as projections of relative urban populations in the year 2010 .

The model requires values of relative total factor productivities. These are deter- 
mined for the initial allocation and then assumed to be constant over time. Hence, I abstract from differential productivity developments across sectors and countries over time. For exogenous initial relative outputs and endogenously determined relative prices, the United States' relative total factor productivity is

$$
\frac{A_{N}^{U}}{A_{T}^{U}}=\left(\frac{Y_{N}^{U}}{Y_{T}^{U}}\right)^{1-\nu} \iota_{U}^{-\nu} .
$$

Other relative total factor productivities are calculated accordingly.

For the international investment positions, the currency denominations thereof and interest return on them I follow Obstfeld and Rogoff (2005). They assume the "exorbitant privilege" with $3.75 \%$ interest paid on US dollar denominated assets and $5 \%$ on assets denominated in all other currencies. These figures are somewhat smaller than the post-war historical average (Gourinchas and Rey, 2006).

\subsection{The Global Rebalancing Scenario}

The first dimension of the results, the global rebalancing scenario in which all current accounts are reduced to zero, is shown in Table 1 and highlighted in Figure 2 for the real exchange rates. The depreciation of the US dollar falls from $38.1 \%$ to $27.5 \%$ (for $\nu=$ 0.7 ) and $23 \%$ (for $\nu=1$ ) respectively when the supply side is allowed to adjust (All values shown are percent changes and calculated as log differences between the initial and the final allocations.). Asia's appreciation, in turn, is significantly reduced, from $24 \%$ to $16.7 \%$ and $13.5 \%$ while Europe's appreciation, already mild without supply response, is further reduced as well.

This reduced real depreciation is achieved through somewhat larger terms of trade deteriorations of the United States vis-à-vis Asia and Europe (Figure 3) and a much lower change in the relative non-tradables prices. The larger change in the terms of trade may appear counter-intuitive at first sight. However, in order for a greater quantity of tradable output to be sold in the world market, a greater price change is necessary. This greater terms of trade change per se contributes to a larger real depreciation of the US dollar, but this effect is more than offset by the reduced change of the relative price of non-tradables, which has a much bigger weight in real exchange rates than the terms of trade due to the large share of non-tradables in the consumption indexes. This underlines the importance of non-tradables in an analysis of current account adjustments and the determination of real exchange rates.

The relative non-tradables price change is a decreasing function of $\nu$. The decline of the US relative non-tradables price falls from $-18.5 \%(\nu=0)$ to $-5.6 \%(\nu=0.7)$ and to basically zero for $\nu=1$. In this latter case the entire adjustment occurs through the quantity adjustment.

The quantity adjustment, in turn, is an increasing function of $\nu$ (see Table 1). The relative quantity of the US non-tradables falls by $13 \%$ while it increases by $4.3 \%$ and $11.4 \%$ in Europe and Asia.

Allowing for price and quantity adjustments does not change the nominal impact (price plus quantity change) compared with the price only adjustment. In case of the US, the fall of the relative size of the non-tradables sector is $18.5 \%$ in all three specifications. However, the specifications introduced here highlight the important role of a 
Figure 2: Change of REER (in \%, short term)

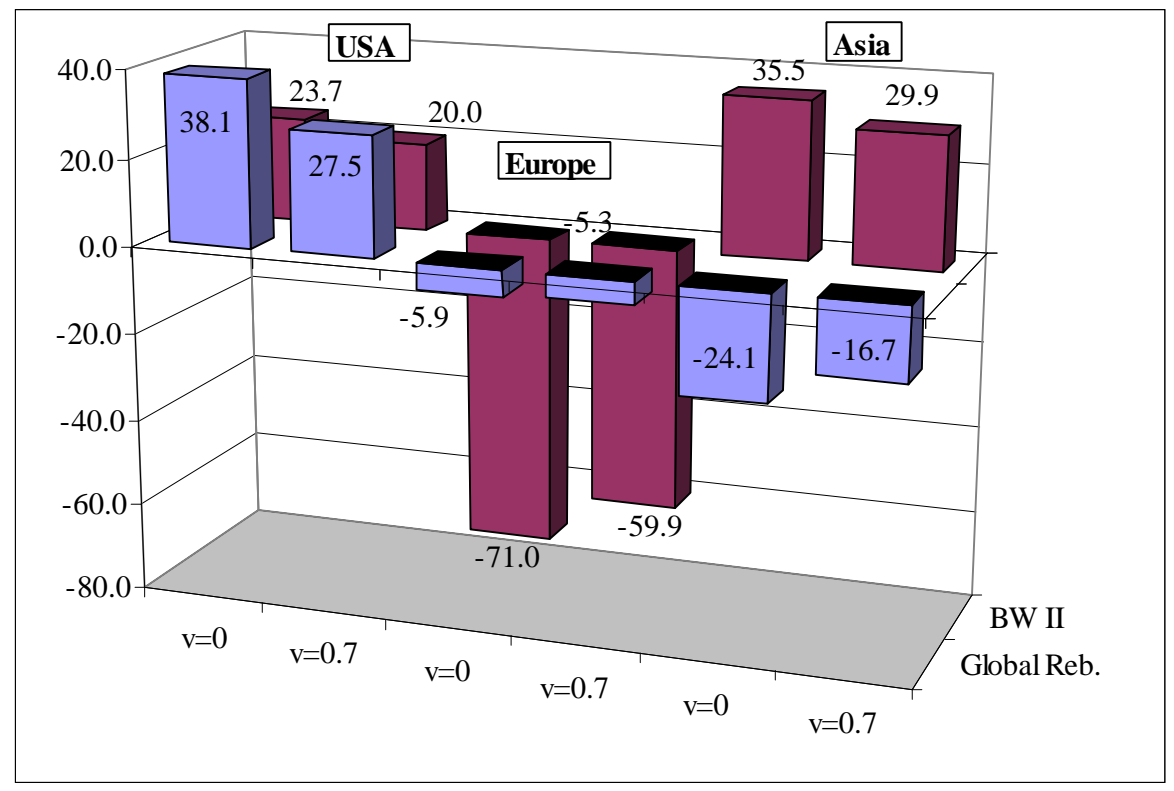

sectoral re-allocation of production factors. Note that in these specifications the least affected region in terms of quantity adjustment is Europe, where the required sectoral re-allocation is extremely low. This will change dramatically in the Bretton-Woods-II scenario.

The relative tradables quantities across regions change remarkably as well. The European and the Asian tradable outputs relative to the US tradables output contracts by $13.1 \%$ and $18.3 \%$ respectively for $\nu=0.7$ and by $18.6 \%$ and $26.3 \%$ respectively for $\nu=1$. Thus, the European and the Asian exporters suffer from the adjustment in the global rebalancing scenario.

The fourth, fifth and sixth columns of Table 1 report results for a simulation as above with the only difference that all current accounts are reduced to half their original values, to -0.1 and to 0.025 for the United States and Europe respectively. Here, the price and quantity changes are reduced by half as well, hence percentage changes of endogenous variables are proportional to the needed adjustment analyzed.

In order to analyze an adjustment scenario that occurs over an extended period, the first part of Table 2 presents simulations where the elasticities of substitution between goods are doubled, $\theta$ is set to 2 and $\eta$ now equals 4 .

In all specifications this reduces the percentage changes proportionally by a little more than $50 \%$. The difference between the US real effective exchange rate change in the specifications with and without supply adjustment is less than above but still significant. Asia's and Europe's adjustment in terms of their respective real exchange rates is quite modest here. However, large factor re-allocations remain necessary in 
Figure 3: Change of bilateral terms of trade (in \%, short term)

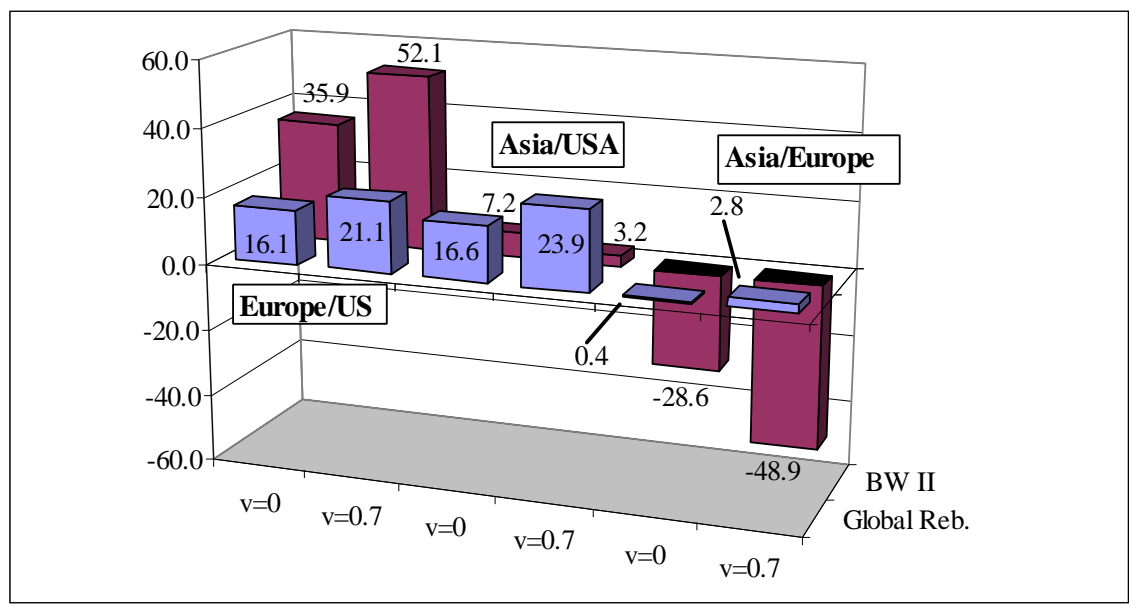

both the United States and Asia, indicated by the percentage changes of the relative quantities of non-tradables of around $8 \%$. Europe, on the other hand, remains almost unaffected with an increase of the non-tradables to tradables ratio $\left(Y_{N}^{E} / Y_{T}^{E}\right)$ of $2.6 \%$. Again, this result will turn out to be sensitive to the choice of the exchange rate regime.

The effect of changing relative labor forces is highlighted by a comparison between the second and third columns. In the third column, a change of relative populations is assumed, taking account of the trend of a rapidly increasing urban population in Asia. Taking this less literally, one could regard this as an analysis of the rapid absorption of the rural Chinese population by the expanding industrial sector. In the global rebalancing scenario, the change in the set-up only has a small impact on relative prices and the relative non-tradable quantities. However, the changes of relative tradables output across regions are remarkable. While in the case of constant populations, Europe's tradables sector grows relative to Asia's $\left(Y_{T}^{A} / Y_{T}^{E}\right.$ falls by $\left.3.8 \%\right)$, this ratio increases by $5.9 \%$ when population changes are introduced. The gains of the US tradables sector vis-à-vis Asia's tradables sector are reduced and, interestingly, Europe's tradables production falls even more relative to that of the United States. Hence, due to the Asian population dynamics, European exporters bear a greater burden in an adjustment scenario. The intuition behind this result is that, ceteris paribus, Asia's relative wages fall (see the wage equations in Section 3.2), resulting in a shuffling of the burden of adjustment away from Asia and towards Europe.

\subsection{The Bretton-Woods-II scenario}

The dramatically different results for a "Bretton-Woods-II" scenario are presented in the second part of Table 1. Here, Asia's central banks keep their bilateral real exchange rates vis-à-vis the United States fixed. The burden of adjustment on the surplus-side is handed over entirely to Europe, which now experiences a real appreciation of almost 
$60 \%$ vis-à-vis both the United States and Asia for $\nu=0.7$ (see also Figure 2) and somewhat less for $\nu=1$. At the same time, this effect is again muted through the quantity adjustment.

The change in the terms of trade between the United States and Asia is now quite modest while the gains in competitiveness of both the United States and Asia vis-à-vis Europe are large. The United States' and Asia's terms of trade fall by about 50\% (for $\nu=0.7$ ) and about $60 \%$ (for $\nu=1$ ), compared with about $30 \%$ when only prices adjust (see also Figure 3).

The weaker US and Asian currencies result in a strong deterioration in Europe's export performance. Compared with the Global Rebalancing scenario, Europe's relative to the US tradables output falls by more than $30 \%$ for $\nu=0.7$ rather than $13 \%$ (see also Figure 4) and by more than $50 \%$ for $\nu=1$. In Asia, the tradables sector continues to grow, a little vis-à-vis the United States and to an enormous extent vis-à-vis Europe.

Figure 4: Europe's burden: Change of bilateral tradable output (in \%, short term)

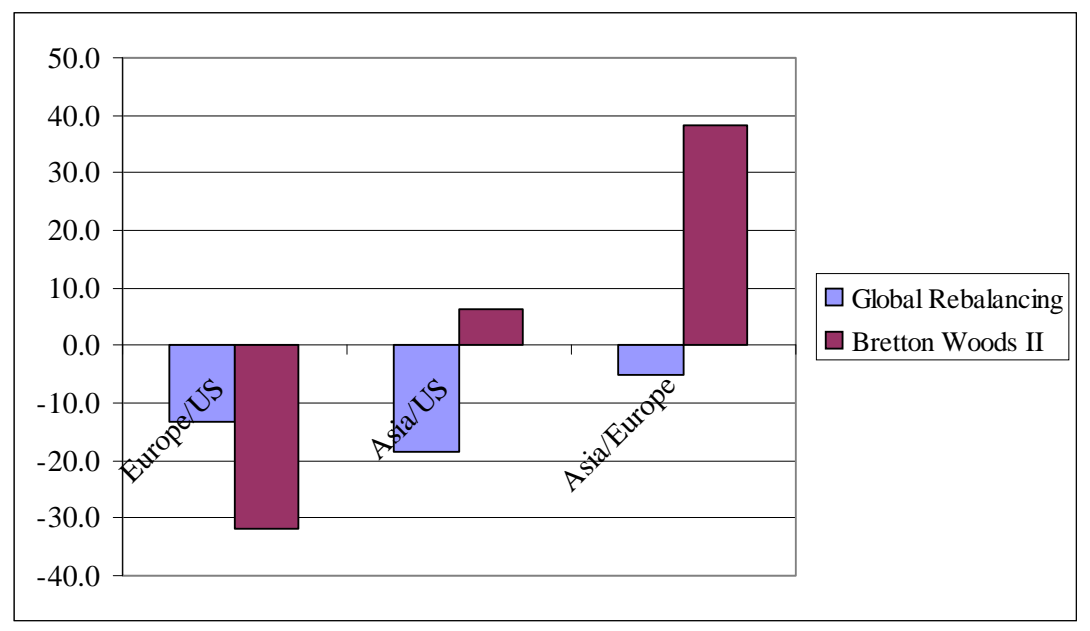

This picture is reinforced by the change of the non-tradable to tradable output ratio. As can be seen in Figure 5, the "burden sharing" between Europe and Asia, with a somewhat bigger burden borne by the Asian economies in the Global Rebalancing scenario, changes completely: the ratio increases by $28.3 \%$ in Europe, while it falls by $23.5 \%$ in Asia for $\nu=0.7$ and even more for $\nu=1$. Thus, under a Bretton-WoodsII scenario, the burden of adjustment in the real economy is handed over entirely to Europe.

Europe's current account surplus of $5 \%$ of US tradables output turns into a deficit of almost $43 \%$, which is roughly $11 \%$ of US GDP (not shown in the table) and a surplus of equal size in Asia. Hence, global imbalances move from one region to another and aggravate by an enormous extent. This would be a truly alarming scenario for the European economies. 
Figure 5: Europe's burden: Change in non-tradable to tradable output (in \%, short term)

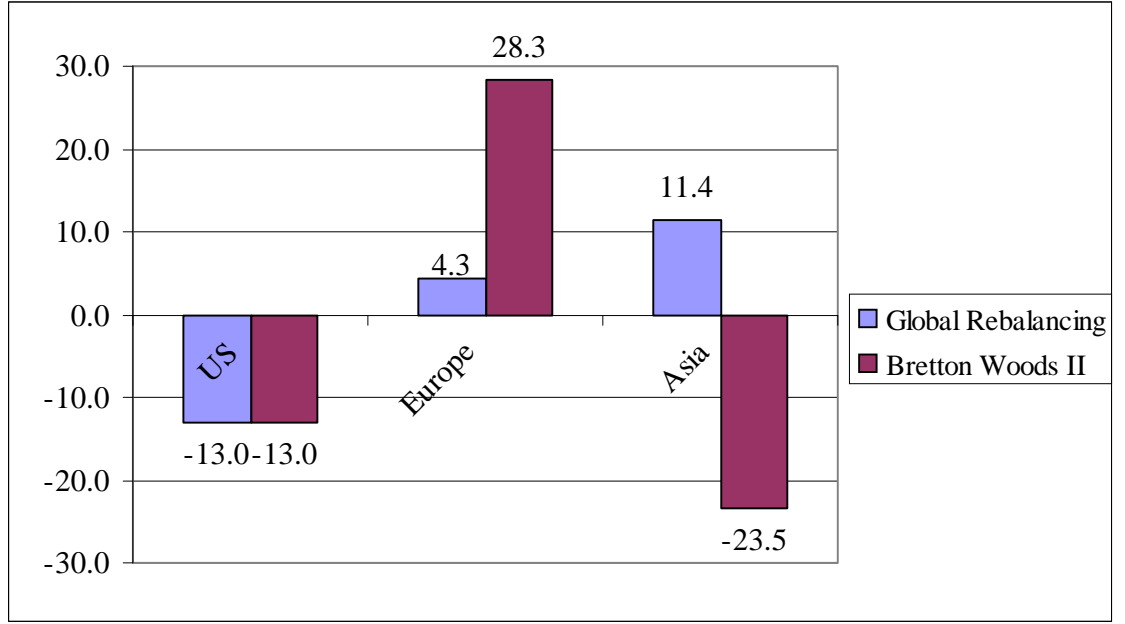

In the last two columns of Table 1, results for the Bretton-Woods-II setup are presented with the US current account reduced to one half of its original deficit. Like under a Global Rebalancing, this reduces the adjustment of all variables by roughly one half. Hence, the amount by which the US deficit is required to fall matters greatly for the amount of stress it creates for the European economy.

Changing the time horizon of the adjustment has similar effects as in the Global Rebalancing scenario (see Table 2). All effects are smaller, but in this case the changing population size only has a small impact on relative tradables output.

\section{Conclusion}

This paper presents a simple but flexible theoretical framework that allows a number of specifications under which a rebalancing of the US current account deficit can be analyzed. The precise way of modelling the reversal is to simply assume that the current account needs to shrink by a certain amount over a given period of time. This required adjustment is exogenous in this model, it may be due to some exogenous change in market sentiment towards the United States.

Three aspects are novel to this approach: First, the model captures a three-country world. The differential impact on Europe and Asia is highlighted, rather than only the impact of a reversal of the US current account on the rest of the world as a whole, as in Engler et al. (2007). Second, the supply side is introduced. Hereby, the sectoral reallocations within countries and across countries are shown, an aspect neglected in the three country model in Obstfeld and Rogoff (2005). Third, the impact of an increasing Asian workforce on the re-balancing scenario is captured through its effect on relative 
wages.

The core result is that exchange rate policies matter for the distribution of the burden of adjustment. While under flexible exchange rates Europe will hardly be affected by the adjustment, a stabilization of Asian exchange rates vis-à-vis the US dollar will exert massive pressure on Europe's tradables sector. European tradables output will not only contract strongly relative to the US tradables output, but also, to a similar extent, relative to Asian tradables output. In the baseline parameterization, this contraction is more than $30 \%$. The supply adjustment does relieve pressure from European exchange rates, that is, reducing the real appreciation, but the implications for the real economy will be devastating if Asian economies do not let their currencies appreciate against the dollar. The flip side of this contraction of the European tradables sector is that the relative size of the non-tradables sector will grow considerably. In the logic of this model, this requires a re-allocation of production factors.

The simulation results reveal a crucial influence of several key parameters and assumptions on the relative burdens of adjustment each country has to bear. First, demand elasticities matter. The smaller the elasticities of substitution between goods are, the greater the implications for exchange rates and factor re-allocation. Since typical estimates for these elasticities are small, the risks implied by the closing of the US current account are indeed significant. However, if one interprets larger elasticities as parameterizations of longer term adjustment scenarios, the risks might not be as severe as the benchmark specification suggests.

Second, size matters. The more the US deficit needs to shrink, the greater the needed adjustment. It follows that if the US deficit needs to shrink only partially, there is also less to worry about factor re-allocation.

Third, size also matters along another dimension which so far has not been highlighted in the literature: relative populations. The increasing Asian workforce tends to reduce its relative wages and increase its competitiveness. In an adjustment scenario this allows Asia to shift a part of the burden of adjustment towards Europe, whose tradables sector is further suppressed.

\section{References}

[1] Caballero, R.J., Farhi, E. and Gourinchas, P.-O., 2006. An Equilibrium Model of "Global Imbalances" and Low Interest Rates, National Bureau of Economic Research Working Paper No. 11996.

[2] Caballero, R.J., Farhi, E. and Gourinchas, P.-O., 2008. An Equilibrium Model of "Global Imbalances" and Low Interest Rates, The American Economic Review 98(1), 358-93.

[3] Dooley, M.P., Folkerts-Landau, D. and Garber, P., 2003. An Essay on the Revived Bretton Woods System, National Bureau of Economic Research Working Paper No. 9971. 
[4] Dooley, M.P., Folkerts-Landau, D. and Garber, P., 2004a. The Revived Bretton Woods System: The Effects of Periphery Intervention and Reserves Management on Interest Rates and Exchange Rates in Center Countries, National Bureau of Economic Research Working Paper No.10332.

[5] Dooley, M.P., Folkerts-Landau, D. and Garber, P., 2004b. Direct Investment, Rising Real Wages and the Absorption of Excess Labor in the Periphery, National Bureau of Economic Research Working Paper No.10626.

[6] Dooley, M.P., Folkerts-Landau, D. and Garber, P., 2004c. The US Current Account Deficit and Economic Development: Collateral for a Total Return Swap, National Bureau of Economic Research Working Paper No.10727.

[7] Dooley, M.P., Folkerts-Landau, D. and Garber, P., 2005a. Savings Gluts and Interest Rates: The Missing Link to Europe, National Bureau of Economic Research Working Papers No.11520.

[8] Dooley, M.P., Folkerts-Landau, D. and Garber, P., 2005b. Interest Rates, Exchange Rates and International Adjustment, National Bureau of Economic Research Working Paper No.11771.

[9] Engler, P., Fidora, M. and Thimann, C., 2007. External imbalances and the US current account. How supply-side changes affect an exchange rate adjustment. European Central Bank Working Paper No. 761 and forthcoming in the Review of International Economics.

[10] Gourinchas, P.-O. and Rey, H., 2006. From World Banker to World Venture Capitalist: US External Adjustment and the Exorbitant Privilege, in: Clarida, R., ed. G7 Current Account Imbalances: Sustainability and Adjustment, The University of Chicago Press, 2006.

[11] Mendoza, E.G., 1991. Real Business Cycles in a Small Open Economy, The American Economic Review 81(4), 797-818.

[12] Obstfeld, M. and Rogoff, K., 2000. The Six Major Puzzles in International Macroeconomics: Is there a Common Cause? in: Ben S. Bernanke and Kenneth Rogoff (eds.), NBER Macroeconomics Annual 2000. Cambridge, MA: MIT Press.

[13] Obstfeld, M. and Rogoff, K., 2005. Global Current Account Imbalances and Exchange Rate Adjustments, Brookings Papers on Economic Activity 1:2005.

[14] Obstfeld, M. and Rogoff, K., 2006. The Unsustainable US Current Account Position Revisited, in: Clarida, R., ed. G7 Current Account Imbalances: Sustainability and Adjustment, The University of Chicago Press. 
[15] Stockman, A.C., Tesar, L.L., 1995. Tastes and Technology in a Two-Country Model of the Business Cycle: Explaining International Comovements, The American Economic Review 85(1), 168-85.

\section{Appendix A.}

The bilateral real exchange rates in the general case of $\theta \neq 1$ are

$$
\begin{aligned}
q_{U, E}= & \frac{\left[\alpha \tau_{U, E}^{1-\eta}+(\beta-\alpha)+(1-\beta) \tau_{U, A}^{1-\eta}\right]^{\frac{1}{1-\eta}}}{\left[\alpha+(\beta-\alpha) \tau_{U, E}^{1-\eta}+(1-\beta) \tau_{U, A}^{1-\eta}\right]^{\frac{1}{1-\eta}}} \\
& * \frac{\left[\gamma+(1-\gamma)\left[\alpha+(\beta-\alpha) \tau_{U, E}^{\eta-1}+(1-\beta) \tau_{E, A}^{1-\eta}\right]^{\frac{\theta-1}{1-\eta}} \iota_{E}^{1-\theta}\right]^{\frac{1}{1-\theta}}}{} \\
& {\left[\gamma+(1-\gamma)\left[\alpha+(\beta-\alpha) \tau_{U, E}^{1-\eta}+(1-\beta) \tau_{U, A}^{1-\eta}\right]^{\frac{\theta-1}{1-\eta}} \iota_{U}^{1-\theta}\right]^{\frac{1}{1-\theta}} }
\end{aligned}
$$

and

$$
\begin{aligned}
q_{U, A}= & \frac{\left[\delta \tau_{U, A}^{1-\eta}+\left(\frac{1-\delta}{2}\right)+\left(\frac{1-\delta}{2}\right) \tau_{U, E}^{1-\eta}\right]^{\frac{1}{1-\eta}}}{\left[\alpha+(\beta-\alpha) \tau_{U, E}^{1-\eta}+(1-\beta) \tau_{U, A}^{1-\eta}\right]^{\frac{1}{1-\eta}}} \\
& * \frac{\left[\gamma+(1-\gamma)\left[\delta+\left(\frac{1-\delta}{2}\right) \tau_{U, A}^{\eta-1}+\left(\frac{1-\delta}{2}\right) \tau_{E, A}^{\eta-1}\right]^{\frac{\theta-1}{1-\eta}} \iota_{A}^{1-\theta}\right]^{\frac{1}{1-\theta}}}{\left[\gamma+(1-\gamma)\left[\alpha+(\beta-\alpha) \tau_{U, E}^{1-\eta}+(1-\beta) \tau_{U, A}^{1-\eta}\right]^{\frac{\theta-1}{1-\eta}} \iota_{U}^{1-\theta}\right]^{\frac{1}{1-\theta}}} .
\end{aligned}
$$

The demand side is fully described by the following equations. For the United States we have

$$
\begin{aligned}
1= & \alpha\left(\alpha+(\beta-\alpha) \tau_{U, E}^{1-\eta}+(1-\beta) \tau_{U, A}^{1-\eta}\right)^{-1}\left(1+r f^{U}-c a^{U}\right) \\
& +(\beta-\alpha)\left(\alpha \tau_{U, E}^{1-\eta}+(\beta-\alpha)+(1-\beta) \tau_{U, A}^{1-\eta}\right)^{-1}\left(\frac{P_{E} Y_{T}^{E}}{P_{U} Y_{T}^{U}}+r f^{E}-c a^{E}\right) \\
& +\frac{1-\delta}{2}\left(\delta \tau_{U, A}^{1-\eta}+\left(\frac{1-\delta}{2}\right)+\left(\frac{1-\delta}{2}\right) \tau_{U, E}^{1-\eta}\right)^{-1} \\
& *\left(\frac{P_{A} Y_{T}^{A}}{P_{U} Y_{T}^{U}}-r\left(f^{U}+f^{E}\right)+c a^{U}+c a^{E}\right)
\end{aligned}
$$


with $f^{U}=F^{U} / P_{U} Y_{T}^{U}, c a^{U}=C A^{U} / P_{U} Y_{T}^{U}, f^{E}=F^{E} / P_{U} Y_{T}^{U}$ and $c a^{E}=$ $C A^{E} / P_{U} Y_{T}^{U}$. For Europe we get

$$
\begin{aligned}
\frac{P_{E} Y_{T}^{E}}{P_{U} Y_{T}^{U}}= & \alpha\left[\alpha+(\beta-\alpha) \tau_{U, E}^{\eta-1}+(1-\beta) \tau_{E, A}^{1-\eta}\right]^{-1} \\
& *\left(\frac{P_{E} Y_{T}^{E}}{P_{U} Y_{T}^{U}}+\left(r f^{E}-c a^{E}\right)\right) \\
& +(\beta-\alpha)\left[\alpha \tau_{U, E}^{\eta-1}+(\beta-\alpha)+(1-\beta) \tau_{E, A}^{1-\eta}\right]^{-1} \\
& *\left(1+r f^{U}-c a^{U}\right) \\
& +\frac{1-\delta}{2}\left[\delta \tau_{E, A}^{1-\eta}+\left(\frac{1-\delta}{2}\right) \tau_{U, E}^{\eta-1}+\left(\frac{1-\delta}{2}\right)\right]^{-1} \\
& *\left(\frac{P_{A} Y_{T}^{A}}{P_{U} Y_{T}^{U}}+\left(-r\left(f^{U}+f^{E}\right)+c a^{U}+c a^{E}\right)\right),
\end{aligned}
$$

and for non-tradables

$$
\begin{aligned}
\frac{P_{N}^{U} Y_{N}^{U}}{P_{U} Y_{T}^{U}}= & \frac{1-\gamma}{\gamma}\left[\alpha+(\beta-\alpha) \tau_{U, E}^{1-\eta}+(1-\beta) \tau_{U, A}^{1-\eta}\right]^{\frac{1-\theta}{\eta-1}} \iota_{U}^{1-\theta} \\
& *\left(1+r f^{U}-c a^{U}\right), \\
\frac{P_{N}^{E} Y_{N}^{E}}{P_{E} Y_{T}^{E}}= & \frac{1-\gamma}{\gamma}\left[\alpha+(\beta-\alpha) \tau_{U, E}^{\eta-1}+(1-\beta) \tau_{E, A}^{1-\eta}\right]^{\frac{1-\theta}{\eta-1}} \iota_{E}^{1-\theta} \\
& *\left(1+\frac{P_{U} Y_{T}^{U}}{P_{E} Y_{T}^{E}}\left(r f^{E}-c a^{E}\right)\right)
\end{aligned}
$$

and

$$
\begin{aligned}
\frac{P_{N}^{A} Y_{N}^{A}}{P_{A} Y_{T}^{A}}= & \frac{1-\gamma}{\gamma}\left(\left[\delta+\left(\frac{1-\delta}{2}\right) \tau_{U, A}^{\eta-1}+\left(\frac{1-\delta}{2}\right) \tau_{E, A}^{\eta-1}\right]^{\frac{-1}{1-\eta}} \iota_{A}\right)^{1-\theta}(\mathrm{A}-5) \\
& *\left(1+\frac{P_{A} Y_{T}^{A}-1}{P_{U} Y_{T}^{U}}\left[-r\left(f^{U}+f^{E}\right)+c a^{U}+c a^{E}\right]\right)
\end{aligned}
$$




\section{Appendix B.}

The general equilibrium conditions derived from equations (1) to (5) and (A-1) to (A-5) are as follows:

$$
\begin{gathered}
=\left[\frac{1-\gamma}{\gamma}\left[\alpha+(\beta-\alpha) \tau_{U, E}^{1-\eta}+(1-\beta) \tau_{U, A}^{1-\eta}\right]^{\frac{1-\theta}{\eta-1}}\left(1+r f^{U}-c a^{U}\right)\left(\frac{A_{N}^{U}}{A_{T}^{U}}\right)^{\frac{1}{\nu-1}}\right]^{\varkappa}, \\
\iota_{E}=\left[\frac{1-\gamma}{\gamma}\left[\alpha+(\beta-\alpha) \tau_{U, E}^{\eta-1}+(1-\beta)\left(\frac{\tau_{U, A}}{\tau_{U, E}}\right)^{1-\eta}\right]^{\frac{1-\theta}{\eta-1}}\right]^{\varkappa} \\
* \\
{\left[\left(1+\left[\left(\frac{w^{E}}{w^{U}}\right)^{-\nu} \tau_{U, E} \frac{A_{T}^{E}}{A_{T}^{U}}\right]^{\frac{-1}{1-\nu}}\left(r f^{E}-c a^{E}\right)\right)\left(\frac{A_{N}^{E}}{A_{T}^{E}}\right)^{\frac{1}{\nu-1}}\right]^{\varkappa}}
\end{gathered}
$$

and

$$
\begin{aligned}
& \iota_{A} \\
= & {\left[\frac{1-\gamma}{\gamma}\left[\delta+\left(\frac{1-\delta}{2}\right) \tau_{U, A}^{\eta-1}+\left(\frac{1-\delta}{2}\right)\left(\frac{\tau_{U, A}}{\tau_{U, E}}\right)^{\eta-1}\right]^{\frac{1-\theta}{\eta-1}}\right]^{\varkappa} * } \\
& {\left[\left(1+\left[\left(\frac{w^{A}}{w^{U}}\right)^{-\nu} \tau_{U, A} \frac{A_{T}^{A}}{A_{T}^{U}}\right]^{\frac{-1}{1-\nu}}\left[-r\left(f^{U}+f^{E}\right)+c a^{U}+c a^{E}\right]\right)\left(\frac{A_{N}^{A}}{A_{T}^{A}}\right)^{\frac{1}{\nu-1}}\right]^{\varkappa} }
\end{aligned}
$$

where $\varkappa \equiv \frac{1-\nu}{\nu+(1-\nu) \theta}$ and which in the case of $\theta=1$ simplify to

$$
\begin{gathered}
\iota_{U}=\left[\frac{1-\gamma}{\gamma}\left(1+r f^{U}-c a^{U}\right)\left(\frac{A_{N}^{U}}{A_{T}^{U}}\right)^{\frac{1}{\nu-1}}\right]^{1-\nu}, \\
\iota_{E}=\left[\frac{1-\gamma}{\gamma}\left(1+\left[\left(\frac{w^{E}}{w^{U}}\right)^{-\nu} \tau_{U, E} \frac{A_{T}^{E}}{A_{T}^{U}}\right]^{\frac{-1}{1-\nu}}\left(r f^{E}-c a^{E}\right)\right)\left(\frac{A_{N}^{E}}{A_{T}^{E}}\right)^{\frac{1}{\nu-1}}\right]^{1-\nu}
\end{gathered}
$$

and 


$$
=\left[\frac{1-\gamma}{\gamma}\left(1+\left[\left(\frac{w^{A}}{w^{U}}\right)^{-\nu} \tau_{U, A} \frac{A_{T}^{A}}{A_{T}^{U}}\right]^{\frac{-1}{1-\nu}}\left[-r\left(f^{U}+f^{E}\right)+c a^{U}+c a^{E}\right]\right)\left(\frac{A_{N}^{A}}{A_{T}^{A}}\right)^{\frac{1}{\nu-1}}\right]^{1-\nu}
$$

Furthermore, we have

$$
\begin{aligned}
1= & \alpha\left(\alpha+(\beta-\alpha) \tau_{U, E}^{1-\eta}+(1-\beta) \tau_{U, A}^{1-\eta}\right)^{-1}\left(1+r f^{U}-c a^{U}\right) \\
& +(\beta-\alpha)\left(\alpha \tau_{U, E}^{1-\eta}+(\beta-\alpha)+(1-\beta) \tau_{U, A}^{1-\eta}\right)^{-1} \\
& *\left(\left[\left(\frac{w^{E}}{w^{U}}\right)^{-\nu} \tau_{U, E} \frac{A_{T}^{E}}{A_{T}^{U}}\right]^{\frac{1}{1-\nu}}+r f^{E}-c a^{E}\right) \\
& +\frac{1-\delta}{2}\left(\delta \tau_{U, A}^{1-\eta}+\left(\frac{1-\delta}{2}\right)+\left(\frac{1-\delta}{2}\right) \tau_{U, E}^{1-\eta}\right)^{-1} \\
& *\left(\left[\left(\frac{w^{A}}{w^{U}}\right)^{-\nu} \tau_{U, A} \frac{A_{T}^{A}}{A_{T}^{U}}\right]^{\frac{1}{1-\nu}}-r\left(f^{U}+f^{E}\right)+c a^{U}+c a^{E}\right)
\end{aligned}
$$

and

$$
\begin{aligned}
& {\left[\left(\frac{w^{E}}{w^{U}}\right)^{\nu}\left(\tau_{U, E} \frac{A_{T}^{E}}{A_{T}^{U}}\right)^{-1}\right]^{\frac{1}{\nu-1}} } \\
= & \alpha\left[\alpha+(\beta-\alpha) \tau_{U, E}^{\eta-1}+(1-\beta)\left(\frac{\tau_{U, A}}{\tau_{U, E}}\right)^{1-\eta}\right]^{-1} \\
& *\left(\left[\left(\frac{w^{E}}{w^{U}}\right)^{\nu}\left(\tau_{U, E} \frac{A_{T}^{E}}{A_{T}^{U}}\right)^{-1}\right]^{\frac{1}{\nu-1}}+\left(r f^{E}-c a^{E}\right)\right) \\
& +(\beta-\alpha)\left[\alpha \tau_{U, E}^{\eta-1}+(\beta-\alpha)+(1-\beta)\left(\frac{\tau_{U, A}}{\tau_{U, E}}\right)^{1-\eta}\right]^{-1}\left(1+r f^{U}-c a^{U}\right) \\
& +\frac{1-\delta}{2}\left[\delta\left(\frac{\tau_{U, A}}{\tau_{U, E}}\right)^{1-\eta}+\left(\frac{1-\delta}{2}\right) \tau_{U, E}^{\eta-1}+\left(\frac{1-\delta}{2}\right)\right]^{-1} \\
& *\left(\left[\left(\frac{\omega^{A}}{\omega^{U}}\right)^{-\nu} \tau_{U, A} \frac{A_{T}^{A}}{A_{T}^{U}}\right]^{\frac{1}{1-\nu}}-r\left(f^{U}+f^{E}\right)+c a^{U}+c a^{E}\right)
\end{aligned}
$$


Appendix C. 


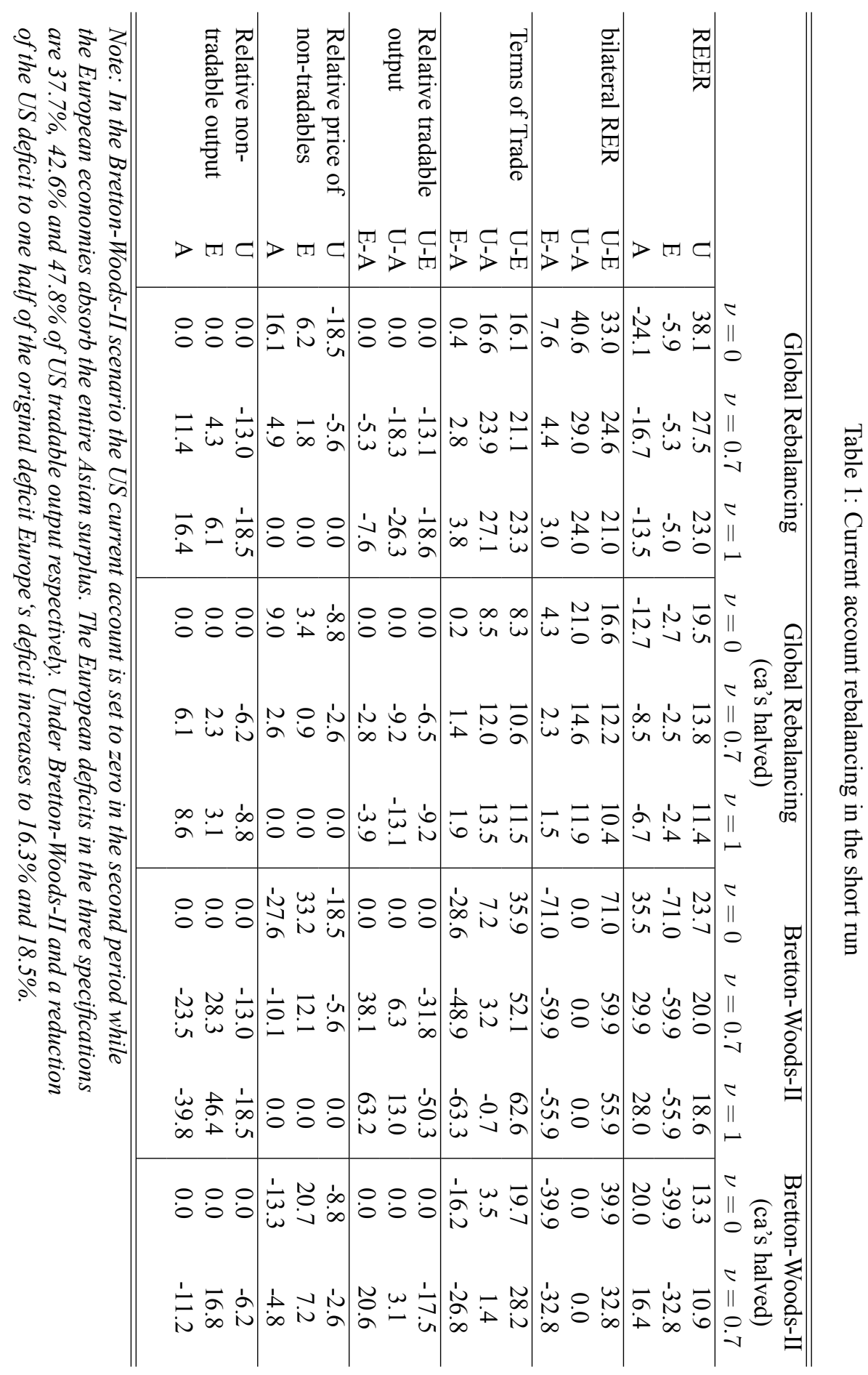


Table 2: Current account rebalancing in the medium run

\begin{tabular}{|c|c|c|c|c|c|c|c|}
\hline & & \multicolumn{3}{|c|}{ "Global Rebalancing } & \multicolumn{3}{|c|}{ "Bretton-Woods-II } \\
\hline & & $\nu=0$ & $\nu=0.7$ & $\nu=0.7^{*}$ & $\nu=0$ & $\nu=0.7$ & $\nu=0.7^{*}$ \\
\hline \multirow[t]{3}{*}{ REER } & $\mathrm{U}$ & 16.9 & 12.9 & 12.3 & 10.5 & 9.2 & 9.3 \\
\hline & $\mathrm{E}$ & -2.2 & -2.0 & -3.2 & -31.6 & -27.6 & -27.7 \\
\hline & A & -11.0 & -8.1 & -6.9 & 15.8 & 13.8 & 13.9 \\
\hline \multirow[t]{3}{*}{ bilateral RER } & U-E & 14.3 & 11.2 & 11.6 & 31.5 & 27.6 & 27.8 \\
\hline & U-A & 18.2 & 13.7 & 12.7 & 0.0 & 0.0 & 0.0 \\
\hline & E-A & 3.8 & 2.5 & 1.1 & -31.6 & -27.6 & -27.8 \\
\hline \multirow[t]{3}{*}{ Terms of Trade } & U-E & 7.1 & 8.5 & 8.9 & 16.0 & 21.1 & 21.3 \\
\hline & U-A & 7.4 & 9.6 & 8.2 & 3.2 & 1.9 & 1.1 \\
\hline & E-A & 0.3 & 1.1 & -0.7 & -12.8 & -19.1 & -20.2 \\
\hline \multirow{3}{*}{$\begin{array}{l}\text { Relative tradable } \\
\text { output }\end{array}$} & U-E & 0.0 & -8.4 & -11.0 & 0.0 & -20.7 & -23.3 \\
\hline & U-A & 0.0 & -12.2 & -5.1 & 0.0 & 3.9 & 9.7 \\
\hline & E-A & 0.0 & -3.8 & 5.9 & 0.0 & 24.6 & 33.1 \\
\hline \multirow{3}{*}{$\begin{array}{l}\text { Relative price of } \\
\text { non-tradables }\end{array}$} & $\mathrm{U}$ & -8.2 & -3.7 & -3.7 & -8.2 & -3.7 & -3.8 \\
\hline & E & 2.5 & 1.1 & 1.0 & 14.8 & 7.9 & 7.8 \\
\hline & A & 7.4 & 3.3 & 3.4 & -12.2 & -6.3 & -5.4 \\
\hline \multirow{3}{*}{$\begin{array}{l}\text { Relative non- } \\
\text { tradable output }\end{array}$} & $\mathrm{U}$ & 0.0 & -8.5 & -8.6 & 0.0 & -8.7 & -8.8 \\
\hline & E & 0.0 & 2.6 & 2.4 & 0.0 & 18.3 & 18.2 \\
\hline & A & 0.0 & 7.8 & 8.0 & 0.0 & -14.7 & -12.5 \\
\hline
\end{tabular}

Note: The European current account deficits in the three Bretton-Woods-II scenarios are $35.5 \%, 39.1 \%$ and $38.2 \%$

* Simulations with changing relative populations. 